\title{
Qualidade e formação como fatores importantes na reestruturação da administração pública portuguesa: o exemplo do setor da saúde
}

\author{
Noemi Alice Oliveira Bonina Costa \\ Faculdade de Tecnologia Senai-Cimatec \\ Jofrina Zinaenda Patrício \\ Mestre em administração
}

\begin{abstract}
As mudanças propostas pelo governo português através da elaboração de um projeto específico de reestruturação para a administração pública refletem o novo olhar que o governo lançava sobre a necessidade de contenção dos gastos públicos em prol da sustentabilidade do Estado, através da promoção da mudança baseada nas componentes qualidade e formação de pessoal como elementos importantes ao processo. Foi utilizado o setor da saúde para exemplificar as alterações propostas que, muito embora sejam demonstradas aqui através de um recorte que remete a este setor, abrangeu toda a estrutura da administração pública. As propostas idealizadas e realizadas por Portugal e submetidas à aprovação da Comissão Europeia foram baseadas em estudos técnicos que procuraram fazer o desenho de toda estrutura e propor as alterações estruturais de forma a diminuir a despesa pública, aumentar os níveis de excelência na prestação do serviço público, garantir a qualidade, promover formação contínua ao quadro de pessoal, promover a sustentabilidade do Estado e, consequentemente, promover o desenvolvimento social.
\end{abstract}

Palavras-chave: reestruturação; administração pública; saúde; qualidade; formação.

Quality and training as important factors in the restructuring of the portuguese public administration: the example of health sector

The changes proposed by the Portuguese government through the development of a specific project for restructuring public administration, reflects the new look that launched the government on the need for restraint in public spending for sustainability of the state, through the promotion of change based on the quality and personnel training, as important to the process. We used the health sector to illustrate the proposed amendments which, although they are shown here in a clipping that refers to this sector, the amendments covering the entire structure of government. The proposals designed and carried out by Portugal and submitted for approval by the European Commission were based

Artigo recebido em mar. 2011 e aceito em jul. 2011.

RAP - Rio de Janeiro 46(1):271-90, jan./fev. 2012 
on technical studies that sought to make the design of the whole structure and to propose structural changes in order to reduce public expenditure, increase levels of excellence in public service delivery ensure the quality, promote continuing education for staff, promote the sustainability of the state and thus promote social development.

KEY WORDS: restructuring; public administration; health; quality; training.

\section{Introdução}

O cenário de mutação contínua deste mundo globalizado exige das organizações, sejam elas privadas ou públicas, posturas e posicionamentos que lhes permitam atender às demandas de mercado e da sociedade.

Nessa conjuntura, às instituições de caráter público — entidades ou empresas públicas — já não é permitido estarem de fora da reestruturação produtiva, entendida como uma nova estruturação em sua forma de atuação em qualquer área em que estejam presentes, sobretudo na área de saúde. Nessa área, que é essencialmente de prestação de serviços, caracterizada por forte demanda por novas tecnologias e constantes pesquisas no intuito de prolongar a vida das pessoas e da qual se exigem respostas rápidas, o processo decisório e a confiabilidade das informações prestadas são estratégicos e essenciais, o que denota a necessidade de buscar novas formas de desenvolvimento em nível organizacional.

As instituições públicas portuguesas vêm passando, ao longo dos últimos anos, por um processo de mudança de atuação e gestão bastante acentuado. A essas instituições vêm sendo "cobradas" posturas de excelência, de crescimento, de capacidade de resposta, que não conseguem ser exercidas caso permaneçam se estruturando com base no modelo inicial clássico de abordagem administrativa e mantenham políticas em relação a seus quadros de recursos humanos também referidas a tal modelo.

Existe um conjunto de instituições que contam com tecnologia de ponta e têm a necessidade de responder rapidamente às demandas dos serviços que prestam. Estas instituições inserem-se num contexto de organizações que têm de ser responsivas, ${ }^{1}$ o que, por seu turno, requer processos decisórios rápidos.

A qualidade e a formação integraram medidas importantes no novo desenho planejado para o setor da saúde, perspectivando novas formas de entendimento e abordagem para os

\footnotetext{
${ }^{1}$ De acordo com Vaitsman e Andrade (2005:606), "o conceito de responsividade é utilizado na ciência política e diz respeito a quanto as ações governamentais atendem às expectativas e demandas da população. A OMS introduziu-o no campo da avaliação em saúde, como uma alternativa ao conceito de satisfação, para se referir aos elementos não diretamente ligados ao estado de saúde. Seu fundamento está no pressuposto de que, além de promover e manter a saúde dos indivíduos, o sistema de saúde deve tratá-los com dignidade, facilitar sua participação nas decisões sobre os procedimentos de saúde, incentivar a comunicação clara entre profissional de saúde e usuário e garantir a confidencialidade do histórico médico. Alguns autores definem responsividade como uma combinação de satisfação do paciente com modo como o sistema age (Blendon et al., 2001)".
} 
enfrentamentos das necessidades de desenvolvimento e sustentabilidade que se ampliaram para toda a estrutura pública portuguesa.

A reestruturação fez-se necessária e entender a reforma geral da estrutura pública, iniciada efetivamente no ano de 2004, no intuito de inserir as mudanças ocorridas, tendo o setor da saúde como exemplo, é essencial neste movimento mais amplo que vem alcançando generalidade na máquina pública em Portugal.

\section{A administração pública portuguesa}

Nenhum país tem as funções públicas idênticas, Bilhim (2007:122) afirma que "a própria União Europeia (UE) não tem metas e objetivos que visem a integração das funções públicas dos diversos países membros, nem da própria administração pública".

Em Portugal, a modernização tem sido estimulada por impulsos exógenos, ou seja, a racionalização da administração foi a forma pensada em virtude de impulsos vindos do exterior como saída para a sustentabilidade do próprio país como Estado-membro da UE, em detrimento da racionalidade política de deixar as coisas irem acontecendo ao longo do tempo sem maiores medidas de sustentação, desde que a manutenção no poder estivesse minimamente garantida (Bilhim, 2007).

Considerando a proposição de Bilhim (2007) de que nenhum país tem as funções públicas idênticas, conhecer a estrutura da administração pública portuguesa é importante para formar um quadro de referência para análise, já que possui suas próprias particularidades e divisões.

A estrutura da área pública apresenta maior complexidade que as estruturas da área privada, pois tem de cumprir papéis e objetivos distintos, já que o interesse público molda a estrutura administrativa pública.

Sendo a administração pública entendida como um sistema de órgãos, serviços e agentes do Estado e das demais pessoas coletivas públicas, se divide nos seguintes níveis, em Portugal, de acordo com Castel-Branco (2008):

、 Serviços de apoio a órgãos de soberania e entidades independentes;

v Administração direta e indireta do Estado;

v Administração regional autônoma - inclui os órgãos de governo próprios das Regiões Autônomas (Região Autônoma da Madeira e Região Autônoma dos Açores) e os serviços e organismos dependentes, direta e indiretamente. As regiões autônomas têm um estatuto político-administrativo próprio e órgãos de governo próprios: Assembleia Legislativa e o Governo Regional;

v Administração Autárquica que abrange 4.259 freguesias, das quais 4.050 no continente e 209 nas Regiões Autônomas e 308 Municípios, dos quais 278 no continente e 30 nas Regiões Autônomas (Castel-Branco, 2008:11). 
A administração pública é fundamental para a instituição e consolidação de um Estado moderno, que age em prol dos cidadãos, que incentiva a excelência do trabalho dos agentes envolvidos e, sem dúvidas, que é promotor do desenvolvimento econômico e social dos países (Poap, 2005). Segundo Castel-Branco (2008), tem por objetivo atender e zelar pelo interesse público, no que respeita aos direitos e interesses garantidos por leis aos cidadãos.

Isso implica o dever de se realizar uma boa administração, ou seja, buscar o bem comum da forma mais eficiente possível. Os órgãos e agentes administrativos, subordinados à Constituição e à lei, devem atuar segundo "os princípios da igualdade, da proporcionalidade, da justiça, da imparcialidade e da boa-fé" (Castel-Branco, 2008:11).

O momento conjuntural atual é de redefinição de estruturas, conforme afirma Lotta (2002:4), "o que antes era marcado por ambientes extremamente técnicos, burocráticos e racionais passa a encontrar exigências de renovação". Assim, objetivos de progressos e de melhores condições de produtividade, de eficiência e de eficácia e até mesmo da própria sustentabilidade das finanças públicas requerem racionalização da máquina administrativa pública.

A modernização da administração pública em Portugal teve suas bases na promoção de novas práticas de gestão e organização com vistas a aproximar o Estado do cidadão, garantir serviços mais eficazes, mais eficientes, mais transparentes, mais céleres e com mais qualidade (Poap, 2005). Para tanto, foi fundamental estabelecer modelos estruturais mais enxutos e orientações de trabalho voltadas para objetivos e resultados fundamentados no mérito profissional.

Para Lotta (2002), a reestruturação também passa pela mudança de atuação dos servidores públicos. Espera-se que o funcionário da área pública seja direcionado para ações marcadas pelo propósito de realizar, ou seja, ao invés de apenas obedecer, o funcionário deve assumir responsabilidades, deixando de ser um sujeito passivo dentro da organização.

A administração pública portuguesa, em particular, caracterizava-se por elevada burocracia, morosidade e baixa qualidade dos serviços prestados, baixa eficiência na utilização de recursos públicos e ainda pouca capacidade de acompanhar e responder com eficácia às mudanças em seu ambiente externo (PEC, 2005; QCA III, 2004). Decisões visando a reestruturação do setor público em Portugal foram tomadas num contexto emergencial para promoção da sustentabilidade e do desenvolvimento do país, que se encontrava numa posição delicada em relação à sua permanência como Estado-membro na União Europeia, caso não tomasse medidas para promover a estabilização econômica.

O país passava, em fins de 2004, por uma grave crise que atingia todos os seus setores, principalmente as finanças públicas, cujo déficit bruto ultrapassava muito significativamente a média europeia e, por isso, merecia atenção redobrada dos seus dirigentes (PEC, 2005). Isto motivou o então presidente da República, Jorge Sampaio, a antecipar a convocação das eleições legislativas para fevereiro de 2005, representando um esforço para estabilizar o governo e, a partir daí, reorganizar as estruturas do país rumo à modernização, ao crescimento e à sustentabilidade.

Devido a esses fatores, somente em junho de 2005, após aprovação pelo Conselho de Ministros e discussão na Assembleia da República, foi apresentada à Comissão Europeia, o 
órgão executivo da União Europeia, o Programa de Estabilidade e Crescimento para o período de 2005 a 2009, dentro do "quadro da supervisão multilateral das posições orçamentais e da coordenação de políticas econômicas na União Europeia" (PEC, 2005:1).

O programa teve como objetivo a adoção de uma estratégia para o desenvolvimento econômico e consolidação das contas públicas, conforme afirma PEC (2005:3), “através da aplicação de medidas e reformas destinadas a enfrentar a atual situação orçamental portuguesa, que é muito preocupante, e a criar condições para um crescimento econômico sustentado".

A intenção do governo era dar continuidade aos programas operacionais apresentados à Comissão Europeia, que se integravam no Quadro Comunitário de Apoio (QCA) para as intervenções estruturais comunitárias, na sua revisão Intercalar de 2004² (QCA III, 2004).

As orientações estratégicas do QCA III se encontravam subdivididas em eixos prioritários que abrangiam, em termos estruturais, os recursos humanos, a atividade produtiva, a competitividade da economia, os transportes e acessibilidades, o ambiente, a sociedade do conhecimento, as assimetrias regionais e a igualdade de oportunidades (QCA III, 2004), ou seja, abrangia todo o meio envolvente da atuação do Estado.

Além disso, o governo lançou uma série de programas com o intuito de nortear as reformulações e orientar a operacionalização da estratégia, observando a transversalidade dos diversos setores e fomentando o trabalho em conjunto para promover a modernização das instituições públicas portuguesas (Poap, 2005; P.O. Saúde, 2005).

O principal objetivo era a contenção da despesa pública de modo a garantir certa sustentabilidade do Estado (PEC, 2005), já que o mesmo passava por uma grave crise orçamental, com índices, em termos de finanças públicas, muito aquém do piso da média europeia.

Foi tendo como referência o contexto até aqui delineado que se deu a reestruturação da administração pública portuguesa, a qual é enfocada a seguir desde seus primórdios até a atualidade.

\section{Reestruturação da administração pública}

A necessidade da reforma já vinha sendo discutida no país, mas seu início foi marcado pela publicação da Resolução do Conselho de Ministros, no 95/2003, de 30 de julho, onde foram definidas e aprovadas as grandes linhas de orientação da reforma e seus objetivos (Poap, 2005).

\footnotetext{
${ }^{2}$ O Quadro Comunitário de Apoio III para Portugal abrangia um período de atuação de 2000 a 2006; em 2004 sofreu uma revisão intercalar. Os programas operacionais foram subdivididos por áreas que abrangiam todo o âmbito de atuação governamental. As áreas ficaram subdivididas, dentro do que o governo chamou de eixos prioritários (QCA III, 2004), em: Educação; Emprego, Formação e Desenvolvimento Social; Ciência, Tecnologia e Inovação 2010; Sociedade do Conhecimento; Saúde XXI; Cultura; Modernização da Administração Pública; Agricultura e Desenvolvimento Rural; Pesca; Modernização da Economia; Acessibilidades e Transporte; Meio Ambiente e Estratégias de Desenvolvimento para as regiões do país (Norte, Centro, Lisboa e Vale do Tejo, Alentejo, Algarve, Açores e Madeira).
} 
Segundo Poap (2005), os objetivos estavam direcionados para promover a missão da busca pela excelência, modernização dos organismos, qualificação e estímulo aos funcionários, inovação dos processos e introdução de novas práticas de gestão. O intuito foi trabalhar a modernização administrativa, "ao nível da inovação organizacional, da simplificação dos procedimentos e da qualificação dos serviços prestados, à formação dos ativos da Administração Pública Central" (Poap, 2005:5).

As bases para a reforma foram lançadas em 2004/05 e ao longo dos anos o governo propôs mais alguns programas que deveriam ser fundamentados em relatórios técnicos para que a reforma do Estado fosse efetivada e operacionalizada (Poap, 2005; P.O. Saúde, 2005; Prace, 2006), apresentando bons resultados de implementação já no final do projeto do QCA, previsto para 2007 (QCA III, 2004).

O país vinha enfrentando muitas turbulências em finais de 2004 com graves reflexos no ano seguinte, como a necessidade de antecipação das eleições legislativas para o mês de fevereiro, conforme já foi visto, cujo novo governo (XVII Governo Constitucional) tomou posse em março de 2005.

Nesse ano, o governo precisava voltar a alinhar-se com as exigências que fazer parte de uma comunidade de países (União Europeia) impõe e procurou submeter os projetos, que deveriam ter sido enviados em dezembro de 2004, para apreciação da Comissão Europeia, ${ }^{3}$ mesmo fora do prazo, tendo como justificativa a crise política por que passava (PEC, 2005).

Assim, em 4 de agosto é publicada nova Resolução do Conselho de Ministros, a de no 124/2005, onde é determinado o início operacional do processo de reestruturação administrativa com vistas a racionalizar as estruturas centrais, valendo-se da descentralização das funções, da desconcentração coordenada e da modernização dos processos.

A descentralização, a desconcentração e a modernização estavam relacionadas à necessidade fulcral de controlar a despesa pública, já que este fator colocava Portugal em uma posição muito delicada na UE, ${ }^{4}$ que poderia acusá-lo de descumprimento das diretrizes basilares

\footnotetext{
${ }^{3}$ É importante salientar que Portugal trabalha em parceria com a Comissão Europeia, respeitando as condições de pertencer, como Estado-membro, a um quadro comunitário, e a intervenção proposta para a administração pública se mostrou pioneira e inovadora no bloco, o que também poderia servir como referencial para outros Estados-membros (Poap, 2005).

${ }^{4}$ A União Europeia (UE), anteriormente designada por Comunidade Econômica Europeia (CEE) e Comunidade Europeia (CE), é uma organização internacional constituída atualmente por 27 Estados-membros. Foi estabelecida com este nome pelo Tratado da União Europeia (normalmente conhecido como Tratado de Maastricht) em 1992 , mas muitos aspectos desta união já existiam desde a década de 1950. A União tem sedes em Bruxelas, Luxemburgo e Estrasburgo. A União Europeia tem muitas facetas, sendo as mais importantes o mercado único europeu (uma união aduaneira), uma moeda única (o euro, adotado por 16 dos 27 Estados-membros) e políticas agrícola, de pescas, comercial e de transportes comuns. A União Europeia desenvolve também várias iniciativas para a coordenação das atividades judiciais e de defesa dos Estados-membros (Figel, 2007).
} 
condicionadoras de sua participação como Estado-membro. Ainda que esses fatores já fossem muito conhecidos, a tomada de consciência sobre os problemas específicos por que passava a administração pública não foi processo linear e rápido.

A estrutura organizacional da administração pública portuguesa se encontrava inchada e pouco funcional em termos de objetividade pois, de acordo com Poap (2005), havia variadas formas de nomenclaturas organizativas, diversos modelos de estruturação e decisão adotados, além de uma hierarquia pesada haver se consolidado.

As implicações negativas dessa forma de trabalho eram crescentes. A coordenação das rotinas de trabalho, as tomadas de decisão interna, a capacidade de resposta às necessidades da sociedade em geral se encontravam prejudicadas em virtude dos múltiplos departamentos com as mesmas funções, que não coordenavam adequadamente suas políticas, acabando por gerar custos desnecessários (Poap, 2005). Fatores estes que representaram pontos de partida fundamentais para modernizar a administração pública.

Contudo, a mudança necessitaria ser articulada e dirigida, pois os modelos de referência em termos organizacionais e decisórios eram escassos, o que era fator de complexificação e, consequentemente, lentidão nas respostas às exigências dos cidadãos. Assim, Poap (2005) afirma que "a utilização das tecnologias de informação e comunicação, a definição e realização de um número limitado de projetos-piloto concretos em áreas estratégicas e a replicação de experiências de sucesso consolidadas são vetores essenciais" (Poap, 2005:7).

O governo reconhecia que essa mudança seria profunda e essencialmente pautada na promoção de uma mudança cultural capaz de provocar uma reviravolta comportamental em seus recursos humanos (Poap, 2005), além de seu rejuvenescimento e qualificação, pois somente assim o esforço seria potenciado de forma apropriada. O processo de implementação de mudanças tão substantivas foi complexo.

A eficiência e a racionalização administrativa podem trazer, entre outros resultados, maior produtividade e capacidade de resposta às necessidades dos usuários de serviços públicos por parte das organizações públicas, além da própria sustentabilidade das finanças públicas, o que, por si só, já é indicativo de preciosa vantagem para o desenvolvimento do país.

Conforme pode ser observado na figura 1, a modernização pressupunha novas práticas de gestão e organização, com ênfase na qualidade dos serviços prestados e na eficiência do consumo e recursos visando uma maior aproximação entre Estado e cidadãos com a garantia de um serviço "mais eficaz, mais eficiente, mais transparente, mais célere e com maior qualidade" (Poap, 2005:11). 
Figura 1

\section{Reestruturação da administração pública}



Fonte: Poap (2005:11).

Assim, os vetores essenciais desenvolvidos na reestruturação, segundo Poap (2005), foram:

\ Organização do Estado;

จ Organização da Administração Pública;

v Inovação e Tecnologia/Governo Eletrônico;

v Liderança e Responsabilidade;

v Mérito e Qualificação;

v Valorização e Formação;

จ Cultura de Serviço.

Os objetivos envolviam ações variadas nos diferentes vetores, tais como definição de novo modelo organizacional que reduzisse as estruturas, agilizando e flexibilizando a organização interna, aumento das competências e responsabilidade dos dirigentes na questão da liderança, introdução de práticas de gestão por objetivos, atualização nas técnicas de gestão e desenvolvimento profissional (formação), simplificação dos procedimentos e formalidades, melhoria nos 
circuitos de comunicação, eliminação de níveis hierárquicos, promoção da qualificação profissional, além de assegurar a transparência, o rigor e a responsabilização (Poap, 2005).

Assim, o lançamento do Programa de Reestruturação da Administração Central do Estado (Prace), em 2006, vem corroborar com os esforços do governo de operacionalizar metas e objetivos propostos.

A administração pública passa a ser vista e entendida a partir de uma perspectiva de reinvenção da governação, onde a nova abordagem coloca o cidadão/cliente como foco nas novas definições de serviço público (Bilhim, 2007). Um exemplo é o caso da saúde pública, em que, de acordo com Joce (2002:L271/4), a nova estratégia proposta pela União Europeia nesta matéria "deve constituir uma oportunidade de reforço da dimensão do cidadão no âmbito da política de saúde da Comunidade [europeia]".

As medidas e ações propostas pelo governo português seriam desenvolvidas em conjunto com outras estratégias e ações tanto do próprio país como ações comunitárias ${ }^{5}$ que fossem relevantes à interação intersetorial sustentada (Joce, 2002), ou seja, a utilização de políticas dos fundos estruturais e a política social da UE poderiam influir de forma positiva nas determinantes da saúde.

O Setor da Saúde é um exemplo dentro do universo da reestruturação geral por que passou a administração pública e reflete o objetivo que o governo tinha de promover a mudança em prol da sustentabilidade e do desenvolvimento.

\section{0 exemplo do setor da saúde em Portugal}

Na maioria dos países, nas diversas partes do mundo, o sistema de saúde é foco de grandes discussões e pauta corrente das agendas governamentais, pois a complexidade de seu funcionamento é um fator crítico para a sociedade, seu crescimento e desenvolvimento.

Além disso, requer a movimentação dos mais variados recursos, figurando com destaque na contribuição para o aumento das despesas públicas, para prover seu funcionamento, sua necessidade de inovação e manutenção. Sem contar o alto custo com recursos humanos e sua dinâmica formativa, necessária à evolução do próprio sistema no atendimento às demandas sociais.

Em virtude disso, o Parlamento Europeu publica, em 2002, a Decisão no 1786/2002/CE que aprova um programa de ação comunitária no domínio da saúde pública para o período 2003-08 (Joce, 2002).

Bilhim (2007) assume que hoje a União Europeia possui legitimidade para fomentar a formação profissional associando este papel da União ao princípio da subsidiariedade. ${ }^{6}$ Assim,

\footnotetext{
${ }^{5}$ Ações das quais faz parte todo o quadro de Comunidades da UE.

${ }^{6} \mathrm{O}$ princípio de subsidiariedade é definido no art. 5ำ do Tratado que institui a Comunidade Europeia. O princípio de subsidiariedade pretende assegurar uma tomada de decisões tão próxima quanto possível do cidadão, mediante a verificação constante de que a ação a empreender em nível comunitário se justifica relativamente às possibilidades
} 
o investimento em matéria de educação vocacional e formação profissional manter-se-á como instrumento de desenvolvimento equilibrado de toda a União. Tudo indica que há potenciais benefícios em termos de competitividade, desenvolvimento e crescimento, embora não sejam garantidos; serão sempre a longo prazo e de difícil medição (Bilhim, 2007:159).

Isso reflete o quanto é importante a reavaliação das estruturas, mas sobretudo atentar para as pessoas que fazem parte dela, e que a constroem cotidianamente, pois, sem elas, o bom funcionamento dos serviços estaria comprometido, bem como a continuidade necessária a um processo de mudança. Essa postura mostra a preocupação por parte da UE em promover o equilíbrio nas ações dos Estados-membros em termos de saúde pública.

A saúde, em Portugal, nos últimos 20 anos registrou significativa alteração, com grandes melhorias no crescimento e desenvolvimento do sistema de saúde (P.O. Saúde, 2005), embora ainda existam graves fragilidades e problemas que colocam o setor como prioritário para as políticas do governo.

O sistema de saúde cresceu e se desenvolveu, entretanto, numa análise rigorosa, através da comparação com os outros países da União Europeia e da identificação dos problemas mais graves, verifica-se que, embora o nível de conscientização da população em relação à saúde tenha aumentado - conscientização entendida aqui como preocupação do usuário com a prevenção antes da ocorrência da doença propriamente dita - , esta ainda se apresenta com grande defasagem no quadro europeu (P.O. Saúde, 2005).

As insuficiências e inadequações afetaram grandemente a eficácia e eficiência do sistema de saúde, algumas das quais foram destacadas por P.O. Saúde (2005), e merecem atenção, já que são fatores condicionantes e norteadores da construção da mudança necessária ao ajustamento do sistema.

Essencialmente, de acordo com P.O. Saúde (2005), destacam-se:

v Manutenção de hábitos e estilos de vida prejudiciais à saúde, o que demonstrou a necessidade de se destacar a importância de criar estruturas e programas de promoção da saúde;

v Sistema de vigilância insuficiente, com atrasos no tratamento dos dados e, consequentemente, na disponibilização dos indicadores de saúde;

oferecidas pelo nível nacional, regional ou local. Concretamente, trata-se de um princípio segundo o qual a União só deve atuar quando sua ação seja mais eficaz do que uma ação desenvolvida em nível nacional, regional ou local - exceto quando se trate de domínios da sua competência exclusiva. Este princípio está intimamente relacionado com os princípios da proporcionalidade e da necessidade, que supõem que a ação da União não deve exceder aquilo que seja necessário para alcançar os objetivos do Tratado. O Conselho Europeu de Edimburgo, em dezembro de 1992, aprovou uma declaração relativa ao princípio de subsidiariedade, que fixa as regras de aplicação. A abordagem decorrente desta declaração é retomada num protocolo do Tratado de Amsterdã sobre a aplicação dos princípios de subsidiariedade e de proporcionalidade, anexado ao Tratado que institui a Comunidade Europeia. Esse protocolo introduz, entre outros aspectos, a análise sistemática do impacto das propostas legislativas no princípio de subsidiariedade e a utilização, na medida do possível, das disposições comunitárias menos vinculativas. Disponível em: <http://europa.eu/scadplus/glossary/subsidiarity_pt.htm>. Acesso em: 3 jun. 2009. 
- Serviços pouco adequados ao rigor exigido no diagnóstico e vigilância do estado de saúde e seus determinantes, assim como a situação da necessidade de os laboratórios cumprirem as novas regras nacionais e comunitárias no que concernia ao controle e fiscalização. Isto tornava indispensável a reorganização dos serviços;

จ Difícil articulação entre os diversos níveis de prestação de cuidados;

v Mecanismos insuficientes de apoio às doenças crônicas degenerativas e de evolução prolongada, pois o país necessitava de um sistema de cuidados continuados multidisciplinar e intersetorial;

- Processo de garantia da qualidade na saúde bastante deficiente, mostrando-se urgente a necessidade de instituir programas sistemáticos de avaliação, monitorização e melhoria da qualidade tanto na prestação de cuidados como em nível organizacional.

Assim, aumentar a capacidade de resposta rápida e coordenada às ameaças para a saúde, fomentar estratégias de saúde integradas e intersetoriais e combater as desigualdades em matéria de saúde (Joce, 2002) deveriam ser pilares motivadores para as ações de reestruturação no setor da saúde em Portugal.

Além dos fatores citados, o Ministério da Saúde possuía uma estrutura administrativa pesada e apresentava como outro desafio a diminuição das estruturas, simplificando e racionalizando os procedimentos administrativos levando em consideração a melhoria da qualidade dos serviços prestados aos cidadãos (Prace, 2006).

De acordo com P.O. Saúde (2005), o sistema de saúde português é constituído por três setores:

O Serviço Nacional de Saúde (SNS), que é proprietário e gestor da maioria dos meios de produção de cuidados de saúde e também o maior comprador de cuidados de saúde produzidos pelo setor privado;

O setor social e o setor privado, sendo este último, em parte, conveniado com o Estado;

- O conjunto de subsistemas, públicos e privados, que abrangem cerca de $22 \%$ dos portugueses e de que são exemplos a Assistência na Doença aos Servidores do Estado (ADSE), o das Forças Armadas e os de algumas grandes empresas públicas e privadas.

O Sistema Nacional de Saúde (SNS) é uma macroestrutura que emprega milhares de pessoas em centenas de estabelecimentos por todo o país e, em virtude do volume de atividades, envolve despesas condizentes com elas, ou seja, gastos altos e pesados à despesa pública.

Seu modelo organizacional, seguindo o que ocorria com a administração pública, era excessivamente burocrático, hierarquizado, sem mecanismos de regulação intrínseca, o que limitava a utilização de instrumentos de gestão moderna, gerando disfunções preocupantes ao governo (P.O. Saúde, 2005). 
O lançamento do Programa de Reestruturação da Administração Central do Estado (Prace), em 2006, foi a concretização da elaboração das novas macroestruturas, que foram trabalhadas tecnicamente com orientações das pessoas de experiência relevante e autoridade científica nas diversas áreas de atividade no país.

O Ministério da Saúde, de acordo com o relatório do Prace, foi considerado uma estrutura atípica, pois possuía uma dimensão central para executar sua missão e as instituições prestadoras de cuidados de saúde que, dependentes dele, eram da abrangência do Sistema Nacional de Saúde (Prace, 2006).

Houve muitas alterações no sentido de enxugar a máquina pública e procurar cumprir com os objetivos da reestruturação de modernização, de melhor atendimento, de mais qualidade, de eficiência e de eficácia. A figura 2 mostra o desenho estrutural em 2006 e o novo modelo organizacional proposto para o Ministério da Saúde e que foi regulamentado após avaliação do relatório final do Prace pelo Conselho de Ministros e legislação posterior.7

Conforme se pode constatar observando a figura 2, houve uma significativa mudança na estrutura do Ministério: alguns organismos foram mantidos com alterações na estrutura interna, outros foram extintos ou transferidos para esferas jurídicas de outros gabinetes, organismos ou ministérios e alguns até foram criados para melhor estruturar as necessidades de existência do Ministério.

Assim, dentro dos objetivos de reestruturação da administração pública, considerando que todos os setores sofreram modificações, no sentido da reconfiguração dos processos de trabalho e enxugamento da máquina pública, o Ministério da Saúde, setor extremamente dispendioso para as contas públicas, em virtude de sua natureza intrínseca, também é redesenhado e otimizado e em consequência tem-se a alteração de esferas de alguns organismos.

Partindo dessas premissas, e na perspectiva de operacionalizar a mudança necessária, um plano estratégico foi definido com metas concretas e objetivos mensuráveis e inovadores, em comparação com os modelos tradicionais de gestão na saúde até então utilizados.

Conforme salienta P.O. Saúde (2005), para alcançar esses objetivos foram efetuadas algumas mudanças na gestão das instituições, além de procurar reorientar a alocação de recursos (figura 2). Para isto, foram instituídos ações e programas: os Sistemas Locais de Saúde, Centro de Responsabilidade Integrada nos hospitais, Novos Modelos de Gestão dos Centros de Saúde e os Programas de Garantia da Qualidade.

A questão da qualidade é uma constante (Joce 2002; Joce, 2004; P.O. Saúde, 2005) nas abordagens definidas para a reestruturação, o que indica um novo olhar sobre a organização e sua forma de atuação junto à sociedade, já que trabalhar no setor dos serviços pressupõe verificar e avaliar a satisfação dos clientes/usuários e procurar, a partir daí, melhorar continuamente a prestação desse serviço.

\footnotetext{
${ }^{7}$ Aprovação ainda em 2006 da Lei Orgânica do Ministério da Saúde.
} 


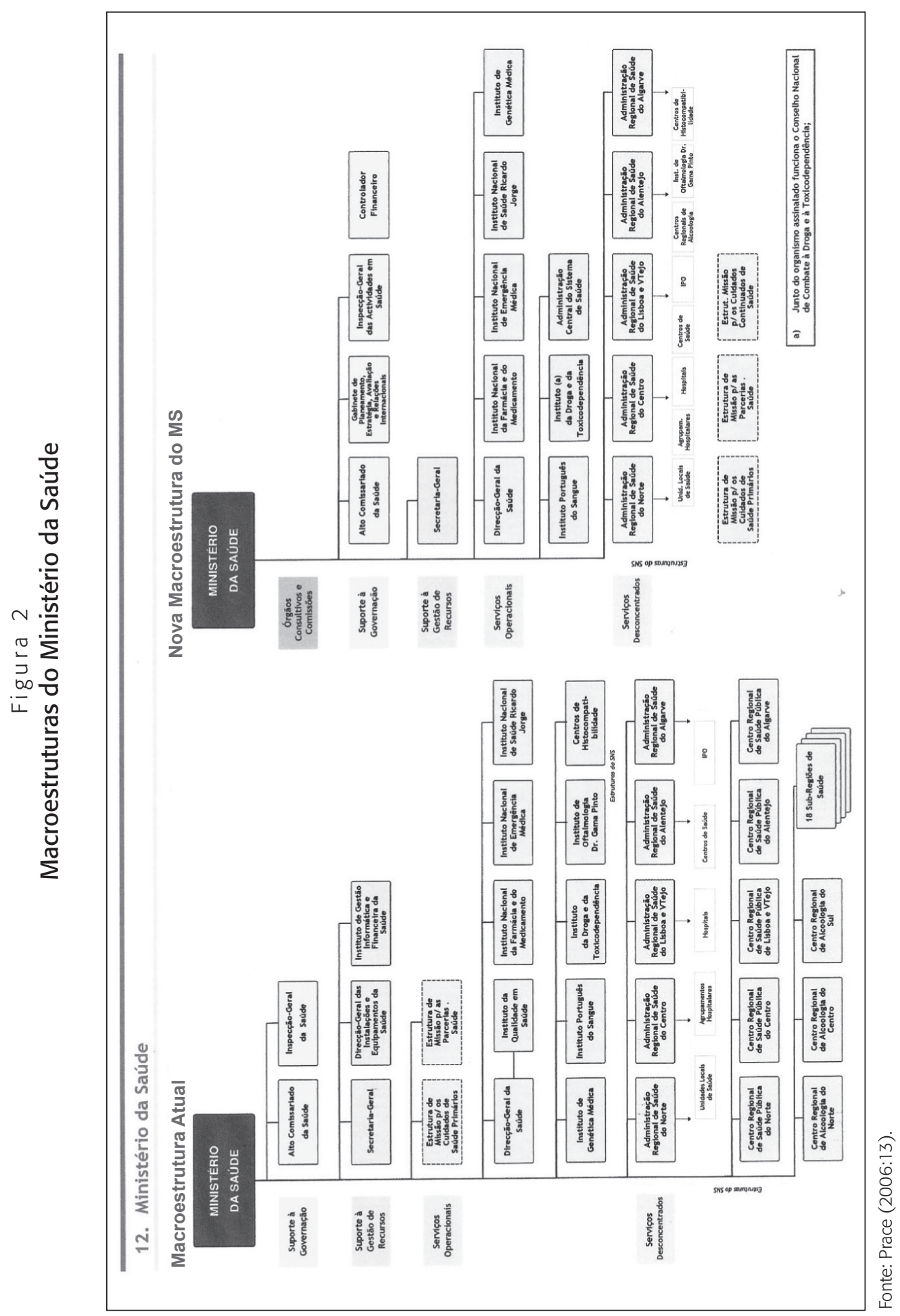

RAP - Rio de Janeiro 46(1):271-90, jan./fev. 2012 
Dentro dessa perspectiva da necessidade de mudar, P. O. Saúde (2005:13) afirma que

o lançamento de Programas de Garantia da Qualidade resultará na melhoria da efetividade dos cuidados de saúde prestados, incentivando a criação de uma cultura de qualidade e desenvolvendo os mecanismos indispensáveis à sua sistematização, baseada na revisão do desempenho e no estabelecimento de metas explícitas.

A ênfase na qualidade aparece no programa operacional para a saúde, lançado na revisão intercalar de 2004 (QCA III, 2004), que veio dar continuidade ao programa lançado no Quadro Comunitário de Apoio II, que compreendia os anos de 1994-99, e trouxe muitas novidades, entre as quais estabelecer como um dos eixos prioritários a melhoria do acesso a cuidados de saúde de qualidade.

Acabou por estabelecer também a certificação e garantia da qualidade e a formação de apoio a projetos de modernização da saúde como medidas essenciais (P.O. Saúde, 2005). Conforme pode ser observado na figura 3, as medidas são inter-relacionadas e interligadas aos problemas estruturais.

Figura 3

Interligação entre os problemas estruturais de gestão e organização e as medidas do P. O. Saúde

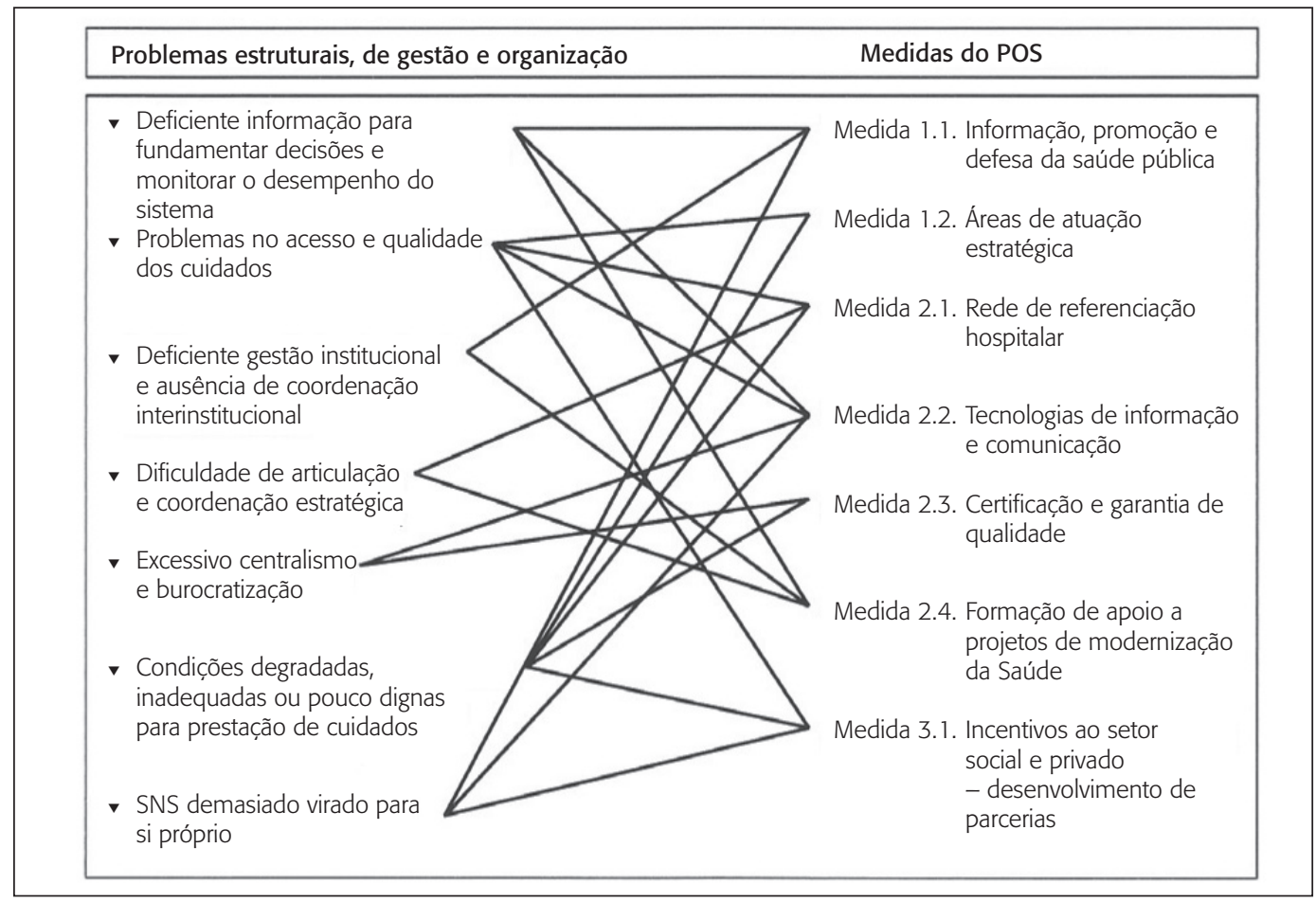

Fonte: P.O.Saúde (2005:73). 
A ação efetiva do Instituto da Qualidade na Saúde (IQS), criado em 1999, se constituiu como um dos fatores essenciais para a consolidação de uma política de qualidade para a saúde.

O QCA III (2004), no programa operacional da saúde, permite pela primeira vez dotar financeiramente uma política de promoção da qualidade em saúde, conforme pode ser observado na Medida 2.3 - Certificação e Garantia da Qualidade (figura 3) com um aporte de aproximadamente 3,8\% das despesas públicas do programa (P.O. Saúde, 2005).

Assim, a qualidade e a formação são consideradas nas medidas de reestruturação como eixos fundamentais para a melhoria e modernização do setor da saúde, ou seja, compõem o conjunto de medidas que ensejaram processos de reestruturação dos serviços da saúde em Portugal.

\section{A qualidade e a formação}

A Medida 2.3 abrigava duas áreas: a certificação/acreditação e os processos de melhoria da qualidade.

Segundo P.O. Saúde (2005), a área de certificação/acreditação dos serviços e laboratórios incluía as ações necessárias à qualificação, ou seja, os diagnósticos, as definições de padrões de normas de referência, os processos de certificação, a adaptação das instalações, as consultorias externas, a melhoria de processos e equipamentos.

A preocupação com a humanização dos serviços de saúde e a segurança de quem a ele recorria e de seus profissionais fizeram com que a área fosse vista como investimento necessário, pois a melhoria contínua da qualidade se traduziria em melhores condições de trabalho, com o aumento da higiene e da segurança e com consequente minimização dos riscos que são associados às atividades de saúde.

De acordo com P.O. Saúde (2005), dentro daquelas ações que não necessariamente implicavam certificação encontravam-se as de desenvolvimento da qualidade:

O desenvolvimento da qualidade caracteriza-se por corrigir erros do sistema e reduzir a variabilidade existente, constituindo uma melhoria permanente, num quadro de responsabilidade e de participação coletiva.

A melhoria contínua da qualidade terá que se basear, portanto, na avaliação sistemática do modo como as atividades de saúde (educação e promoção da saúde, prevenção da doença, diagnóstico, tratamento e reabilitação) influem nos níveis de saúde e na satisfação dos cidadãos e das comunidades em relação aos serviços e ao sistema de saúde. (P.O. Saúde, 2005:36).

Os objetivos gerais da Medida 2.3 foram delineados para abarcar o atendimento às necessidades de agir visando a melhoria da qualidade organizacional (P.O. Saúde, 2005), com a observância da satisfação dos profissionais do setor, ou seja, atentar para o grau de envolvimento dos profissionais das entidades, em particular os do quadro dirigente e da satisfação dos usuários. 
Alguns objetivos foram delineados para este fim, conforme P.O. Saúde (2005):

v Promover a criação de sistemas de garantia da qualidade;

- Dotar os serviços de saúde das condições necessárias à sua adequação aos padrões de referência exigidos pelos sistemas de garantia da qualidade;

、 Desenvolver e consolidar a rede de recursos de conhecimento em saúde.

Estes objetivos pretendiam atender às necessidades de implementação de boas práticas e de normas comunitárias para as atividades ligadas ao sistema de qualidade (Joce, 2004; P.O. Saúde, 2005).

Considerando que nas instituições de saúde, onde o serviço é oferecido para pessoas fragilizadas pela doença e vulneráveis com a situação, mais do que em qualquer outra organização, o fator humano é essencial (Bertelli, 2004). A Medida 2.4 - Formação de Apoio a Projetos de Modernização da Saúde, que pode ser visualizada na figura 3, também merece atenção.

As diretrizes são conducentes ao esforço de qualificação dos profissionais e isto implica desenvolvimento de programas de formação capazes de assegurar a aquisição e desenvolvimento de competências necessárias para este processo de mudança.

As exigências das intervenções da saúde na sociedade, em virtude de sua própria evolução, requerem participação de cidadãos integrados em estruturas organizadas com a possibilidade de prestar serviços complementares à atuação dos serviços de saúde e que devem estar convenientemente preparados (P.O. Saúde, 2005).

Levando-se em conta que o fator principal no setor de serviços, em qualquer ramo de atividade, é o fator humano, sua intervenção como profissional e indivíduo participante do meio social traz alguns elementos para o meio, conforme afirma Bertelli (2004:101):

O recurso humano combina três fatores: traços de personalidade que traz para o trabalho (energia, inteligência, confiabilidade, responsabilidades, atitude normalmente positiva), habilidade em aprender (aptidão, imaginação, criatividade, prudência, sensatez) e a motivação para compartilhar informações e conhecimentos (espíritos de equipe e orientação para metas).

Neste sentido, a Medida 2.4 fomenta a necessidade de formar e apoiar os profissionais, mais especificamente os pertencentes aos quadros dirigentes, pois seu papel é fundamental para a motivação e promoção do comprometimento (Bertelli, 2004).

As funções de liderança e gestão das instituições são essenciais ao processo de mudança. Para prestar serviços de saúde com qualidade, sabe-se que é necessário que as pessoas estejam qualificadas e motivadas para que sejam adquiridos altos padrões de qualidade baseados no comprometimento com a qualidade dos serviços (Bertelli, 2004; Reis, 2004).

Contudo, os diversos profissionais também seriam contemplados com ações formativas — cursos, seminários, investigação/ação —; desde que se integrassem nos objetivos da medida, poderiam ser aprovados (P.O. Saúde, 2005). 
Com a estrutura já delineada, o governo, então, buscou concretizar as ações publicitando os estudos técnicos que foram realizados para que fosse possível dimensionar as novas estruturas para posterior regulamentação legal.

Os estudos foram divulgados como relatórios divididos pelos vários setores, ou macroestruturas, integrantes da administração central, no Programa de Reestruturação da Administração Central do Estado (Prace), em 2006, conforme dito anteriormente.

O estudo técnico foi realizado, respeitando a Resolução do Conselho de Ministros, $\mathrm{n}^{\circ}$ 124/2005, para todas as estruturas que abrangiam a administração pública, e explicitava como seriam seus novos desenhos e a justificativa para tal, cujo exemplo mostrado foi a estrutura do Ministério da Saúde (figura 2).

Essas duas medidas são exemplos muito significativos do patamar em que se encontrava a expectativa e discussão da mudança na administração pública portuguesa e seu retorno para a sociedade (Poap, 2005) com novas perspectivas de alterações de posturas e posicionamentos, cujas bases seriam a prática da qualidade e o investimento na formação de seus velhos e novos quadros de colaboradores.

Estas novas perspectivas levantadas nortearam o trabalho de implementação e consolidação desenvolvido a partir de então pelo Estado português da modernização das estruturas públicas em prol da promoção da eficácia, eficiência, desenvolvimento e sustentabilidade do país.

\section{Considerações finais}

A decisão portuguesa de promover uma mudança estrutural em seu sistema de gestão na área da administração pública representa um marco, tanto para a UE como para o próprio país. Representa o esforço de alavancar a economia portuguesa em níveis aceitáveis dentro do bloco com eficiência, eficácia e sustentabilidade a partir desta mudança.

Admitir que a mudança era a saída para iniciar a contenção dos gastos públicos foi o reflexo da maturidade dos dirigentes do país e da confiança da Comissão Europeia na proposta.

Apostar no redesenho das estruturas, tratando de temas como formação e qualificação de pessoal e qualidade na prestação de serviços, remete a uma ampliação da visão rumo às novas perspectivas para a gestão na Administração Central do Estado, otimizando sua atuação enquanto provedor do bem-estar social. Demonstrada na preocupação governamental de caminhar no sentido da evolução da prestação dos serviços da esfera pública.

A iniciativa de modernizar, muito embora, conforme visto, abrangente a toda estrutura pública portuguesa, é refletida no exemplo do setor da saúde, que, dado seu peso substancial nas despesas públicas, foi escolhido para representar o universo dos setores aos quais foram propostas as mudanças a partir dos estudos técnicos publicados em 2006.

A qualidade, tanto na prestação como na geração do serviço, e a aposta na formação dos quadros de pessoal visando a melhoria do atendimento e a participação ativa do funcionário como agente de mudança e melhoria contínua dos serviços são elementos importantes

retratados e fomentados na reestruturação, demonstrando as novas abordagens de gestão 
admitidas pelo governo português, baseadas na liderança, na responsividade e na melhoria dos serviços.

As instituições são assim instadas a se reconstruírem internamente com bases mais sólidas e democráticas visando a excelência, o crescimento, o aumento da capacidade de resposta, os quais não conseguem ser exercidos caso as mesmas permaneçam se estruturando com base no modelo inicial clássico de abordagem administrativa e mantenham políticas em relação a seus quadros de recursos humanos também referidas a tal modelo.

O enxugamento das estruturas sinaliza a otimização dos recursos, conforme pôde ser observado no exemplo do setor da saúde, e na simplificação de procedimentos, em prol da excelência da prestação do serviço, da sustentabilidade dos organismos e do desenvolvimento geral do país.

Com isto, Portugal buscou lançar as bases para a retomada do seu crescimento, a partir da reestruturação interna com objetivo de solidificar as bases institucionais e impulsionar a atuação do país tanto no cenário da União Europeia como no mundo, promovendo a contenção dos gastos públicos e a sustentabilidade. Os reflexos dessas mudanças ainda estão se fazendo sentir, já que as mesmas se encontram em curso, e implica além das mudanças físicas e institucionais uma reeducação da sociedade para as novas formas de governação inerentes ao processo de mudança. Assim, o país almeja elevar sua posição estratégica em relação aos outros Estados-membros da UE estando a administração central comprometida com seu fim último de contribuir para a consolidação do Estado moderno, que age em prol dos cidadãos, que incentiva a excelência do trabalho dos agentes envolvidos e, sem dúvidas, que é promotor do desenvolvimento econômico e social do país, ou seja, assumiu o compromisso de realizar uma boa administração, cujo intuito é buscar o bem comum da forma mais eficiente possível.

\section{Referências}

BERTELLI, Sandra Benevento (Coord.). Gestão de pessoas em administração hospitalar. Rio de Janeiro: Qualitymark, 2004.

BILHIM, João Abreu de Faria. Gestão estratégica de recursos humanos. 3. ed. Lisboa: Instituto Superior Sociais e Políticas, 2007.

CASTEL-BRANCO, Teresa (Coord.). Caracterização dos recursos humanos da administração pública portuguesa 2005. Lisboa: DGAEP — Ministério das Finanças e da Administração Pública, 2008.

DALE, Barrie; COOPER, Cary. Qualidade total e recursos humanos. 1. ed. Lisboa: Editorial Presença, 1995.

DECRETO-LEI n 129/77 (DL 129/77). D. R. I Série. 78 (77-02-02) 683-686.

FIGEL, Ján. Portal da União Europeia. 2008. Comissário Europeu para a Educação, Formação, Cultura e Multilinguismo, 2007. 
GIRALDES, Maria do Rosário. Avaliação do SNS em Portugal: equidade versus eficiência. Revista Portuguesa de Saúde Pública, v. 23, n. 2, jul./dez. 2005.

GRAÇA, Luís. Políticas integradas de proteção e promoção da saúde e segurança do trabalho nas empresas portuguesas. Revista Portuguesa de Saúde Pública, vol. temático, n. 6, 2006.

JOCE. JORNAL OFICIAL DAS COMUNIDADES EUROPEIAS. 2002. De 9 out. 2002. Decisão nº 1786/2002/CE do Parlamento Europeu e do Conselho de 23 de setembro de 2002.

JOCE. JORNAL OFICIAL DAS COMUNIDADES EUROPEIAS. 2004. De 7 abr. 2004. Diretiva n ${ }^{\circ}$ 2004/23/CE do Parlamento Europeu e do Conselho de 31 de março de 2004.

LOTTA, Gabriela Spanghero. Avaliação do desempenho na área pública: perspectivas e propostas frente a dois casos práticos. RAE Eletrônica, São Paulo, v. 1, n. 2, p. 1-12, 2002.

OLIVEIRA, Maria Marly de. Como fazer projetos, relatórios, monografias, dissertações e teses. 3. ed. Rio de Janeiro: Elsevier, 2005.

MARQUES, A.H. de Oliveira. História de Portugal. 6. ed. Lisboa: Palas, 1981. v. III.

MATTOSO, José. História de Portugal. Lisboa: Ediclube, 1993. vs. XIII e XIV.

PEC. PROGRAMA DE ESTABILIDADE E CRESCIMENTO. 2005-2009. República Portuguesa. Lisboa, 2005.

POAP. PROGRAMA OPERACIONAL ADMINISTRAÇÃO PÚBLICA. Direcção-geral do Desenvolvimento Regional. Lisboa: Editorial do Ministério da Educação, 2005.

P.O. SAÚDE. PROGRAMA OPERACIONAL SAÚDE. Direção-geral do Desenvolvimento Regional. Lisboa: Editorial do Ministério da Educação, 2005.

PRACE. PROGRAMA DE REESTRUTURAÇÃO DA ADMINISTRAÇÃO CENTRAL DO ESTADO. Relatório sectorial final — Ministério da Saúde. Lisboa, 2006.

QCA III. QUADRO COMUNITÁRIO DE APOIO PORTUGAL 2000-2006. Revisão intercalar 2004. Lisboa: Editorial do Ministério da Educação, 2004.

QUIVY, Raymond; CAMPENHOUDT, Luc Van. Manual de investigação em ciências sociais. 3. ed. Lisboa: Gradiva, 2003.

REIS, António. Portugal contemporâneo. Lisboa: Alfa, 1989. v. V.

REIS, Vasco Pinto dos. Gestão em saúde. Revista Portuguesa de Saúde Pública, v. 22, n. 1, jan./jun. 2004.

ROESCH, Sylvia Maria Azevedo. Projetos de estágio e de pesquisa em administração: guia para estágios, trabalhos de conclusão, dissertações e estudos de caso. 3. ed. São Paulo: Atlas, 2006.

SECCO, Lincoln. A Revolução dos Cravos. São Paulo: Alameda, 2004.

TENGARRINHA, J. Os caminhos da Unidade Democrática contra o Estado Novo. Revista da História das Ideias, Coimbra, v. 16, p. 387, 1994. 
VAITSMAN, Jeni; ANDRADE, Gabriela Rieveres Borges de. Satisfação e responsividade: formas de medir a qualidade e humanização da assistência à saúde. Revista Ciência \& Saúde Coletiva (on-line), Rio de Janeiro, v. 10, n. 3, p. 599-613, 2005.

Noemi Alice Oliveira Bonina Costa é professora da Faculdade de Tecnologia Senai-Cimatec. E-mail: noemi_alice@yahoo.com.br.

Jofrina Zinaenda Patrício é mestre em administração, enfermeira e pesquisadora. E-mail: jofrina@sapo.pt. 